\section{A new approach to small business development in South Africa}

\author{
Malcolm Harper
}

\section{Extracts from a speech delivered in the field of small business development by Professor Malcolm Harper at the University of the Witwatersrand}

I would like, first of all, to present you with some very broad, perhaps unrelated, and certainly ill-based conclusions to which I have come. They are based on very little experience, probably wrong, but I often think that if one argues and someone tells you that two and two is five, it perhaps gives you an opportunity to deepen your understanding of the reasons why two and two is four, not five. So I shall present these conclusions without apologies:

Black owned businesses are quasi-monolopolist and highly profitable. A proved over-generalization, but based on one or two admittedly wholly anecdotal observations. Among traders I have heard of an average $20 \%$ gross mark-up, $15 \%$ mark-up items are viewed as some kind of thing we have to sell because the customers need it. I am used in other developing countries, to 1 and $2 \%$ gross margin items being the rule, the few good lines being 15 to $20 \%$. I have observed in the one or two manufacturing enterprises I visited phenomena such as a fellow who is doing very simple, howbeit extremely competent manipulation of wire into springs or something, being able to sell the finished product for eight times the cost to him of the coil of wire. And that proportion of added value to so simple an operation appears, on the face of it, well ... extremely generous. I have observed a knitting enterprise where in two or three hours they could convert, with a very simple machine for which they are paying R25 a month rent, R2 worth of wool into R11 worth of sweater. That is a nice piece of business!

The prices, with the exception of the traders, were set by the competition, by the modern sector competition. Why this is so, well you know better than I. If you agree with my broad conclusion, planning restricts opportunities, there isn't as much competition as there ought to be. The recent move towards liberalization in South Africa, if it is liberalization, has not been fully reflected in the field, or is perhaps not fully appreciated in the field by those whom it is meant to benefit and there is a tradition amongst Black people of reaction rather than initiative. The implication is that, first of all, existing businesses are fact, and need to be prepared for the competition which undoubtedly, one hopes, they are going to face and secondly, that there is a need, not only to help existing businesses but perhaps, more importantly, to create new business, to provide competition and to lower prices. There is no need, I will submit, for heavily sub- sidized loan schemes, provision of premises or other services. These services are needed, but particularly as far as capital is concerned, the return on capital that is possible in small ventures in this country is such that there is absolutely no need to subsidize rates of interest and one must - and this is, I guess, a matter of allowing rather than promoting - encourage in this country the swarming informal sector of competitive manufacturing and trading enterprises that is so much a feature of most poorer countries and which is almost totally absent here. The most obvious contrast between Soweto and a similar community in any other part of Africa is its space. It isn't full of people in the same way. There is a certain number, but areas are not full of people who are busy hawking, selling, peddling, making, repairing or whatever. This sort of activity is valuable both in terms of the service it provides and, of course, the employment and the competition it also provides.

Black trading enterprises are operated at a level typical of an industrialized rather than a developing country. Again based on a tiny sample, but worth stating if only for you to confirm in your own minds that the opposite is the case.

It may only be skin deep, but my perception of the trading enterprises in Soweto which I visited, was that their whole mode of operation, their scale, the neatness, the goods stocked and everything, is typical of a corner grocery store in a workingclass suburb in London or Detroit rather than of a similar operation in Nairobi or Lagos. They are not using accounts to make every or any decision, but what operator of a corner grocery store is? They may not have the most neatly kept or up-to-date books, but take me to a corner grocery store in a working class suburb of London or Detroit and show me one that is. I think the implications from this is that it is not appropriate to apply standard developing country solutions to any problems, including Black, in this country. Because of the schizophrenic nature of this society, if I may so describe it, you can't say that the Black community is another developing country to which we can apply that which works in Kenya, Tanzania or India for that matter.

Major need of Black-owned manufacturing enterprises is for linkages with the modern sector. So often it appears to me that they don't know where to get things, they don't know where to sell things, or if they do know, more importantly, there are barriers in terms of confidence, of actual physical access, but mainly $I$ think in terms of people's perception of their own role which prevents them from going and knocking on the door of the purchasing agent of a large scale company or indeed of the bank manager or of the sales department. I think the implications of this are, first of all, that any form of training must endeavour to break down this personal diffidence as well as actually imparting learning skills and secondly, that the real barriers that do exist must, of course, be removed.

High-level segments of intent by public and private sector organizations are not always matched by practical support in the field. I would say, and I did not hear the statistics before, that although five loan applications 
were approved doesn't sound like a great achievement, I would say from my brief acquaintance here that to get five loan applications approved for Black enterprises is a massive achievement. Congratulations. But let me refer to an example in Kenya where a British-owned bank which appears in its annual report to be massively committed to the cause of Africanization of enterprise in Kenya and Africa in general and which publishes beautiful glossy brochures about its programmes and indeed has headquarters staff in Nairobi devoted to business development, nevertheless threw out, most rudely, an African, a humble rather old man whom I happen to know, who wanted to open a savings account. They threw him out of the office, almost bodily, because he only had 350 shillings and not 499 which is the minimum they require. A typical example of what happens when the policy of the branch is not quite the same as what is said at headquarters. Or a typical example of the United Kingdom where a large multi-national company which gives large sums of money, makes prominent and important statements upholding the cause of small enterprise in the United Kingdom at the same time as at its branch level, a massive cost-reduction programme was undertaken which eliminated all direct dealings with accounts under a certain amount of business a year. In other words, what was happening in the field was not quite the same as what was being talked about in headquarters. One of the implications of this, I think, is that it is important not to talk only to the senior level represented in this room, but to all levels, in public and in private organizations and, of course, on government and administration boards etc. that are concerned with this same sort of thing. I think also that some organization is necessary. I could refer to the State Bank of India when faced with this problem; it laid down that $1 \%$ of the loan portfolio of every branch bank should be of loans made to what they call the 'weaker sector' which, for political reasons, there is not quite the like here, but you have a similar sector. And surprise, surprise managers who had to achieve the $1 \%$ found they were making a lot of money out of it and now, in most cases, have reached $2 \%$. Maybe that sort of imposition as opposed to encouragement in glossy brochures is required.

So, without giving you a chance to contradict those broad generalizations let me talk a little about what might be done.

First of all, let me say a little bit about what should not be done. I think that the timing of my visit is fortuitous: small business is a popular subject throughout the world but particularly pertinent right here, right now. One hears it mentioned everywhere, one sees things in the paper about the Small Business Development Corporation being set up or proposals re new roles in the field. I think there is a danger. Perhaps there isn't in this country, but I have certainly seen it in many other countries that government and indeed society in general should, in its efforts to promote small business, act a little like the driver of a large and expensive motor car who might run me down in the street and then carefully pick me up and take me to the most expensive hospital and pay all the bills. It is right for him to pay the bills, but I'd just as soon he didn't run me down in the first place. That's a little like the way in which we sometimes operate towards small enterprises, I think. Of course, the problem is that not running you down in the first place in South Africa includes a whole lot of legislation and custom etc. which goes a great deal beyond its effects on small enterprise, but I would suggest that actively and expensively to promote small enterprise through positive interventions without removal of the barriers to enterprise, without creating an environment in which enterprise can effectively operate, is not only a waste but is actually - well depending upon your political views - a negative thing. One might go as far as to say that the major effect of such promotional effort without a removal of the barriers is to increase the funds available for the purchase of armaments to make the revolution quicker and cleaner. The removal of barriers has got to go along with, or even precede, the positive interventions which is the subject of what we are talking about today. So, with that priviso, and $I$ think it is an important one, let us look at some of the possible positive interventions assuming, as I say, that everything possible is being done to remove the negative barriers. Let us look at the more positive interventions which can be used to promote small enterprise. An enormous amount of experience has been gathered and documented in conferences of numerous dimension and books too unreadable to describe about this effort throughout the world, but, as I said earlier, South Africa is, unfortunately, or should we say perhaps fortunately, unique and we cannot therefore blindly adopt a programme that has worked in India or Malasia or even in Zambia or Kenya and apply it here. The total range includes industrialists, state loan guarantee programmes, subsidized loan schemes, preferential purchases, reserved industries and enterprise zones. One could go on and on. It is an enormous range of tools at the disposal of anybody who wants to try to promote small enterprise. Or perhaps someone who wants to try and build a bureaucracy to guarantee his own future. There is a need for integration or at least the co-operation and sharing of ideas, but I think there is not a need for a massive organization to do all these things or even a large number of them on a large-scale, national basis and, least of all, is there a need for government to set up such a large massive organization. Experience in both developed and undeveloped countries is that where bureaucracy looks after small business development, corruption is endemic. If I may quote two strange bedfellows, or perhaps misquote them, I think Mao Tsetung said 'Let 1000 flowers bloom and let a 1000 ideas contend', and Ronald Reagan said 'Government is not the solution to our problems, government is the problem'. I think both have something relevant to the promotion of small enterprise.

The most effective way to promote small enterprise is for large numbers of committed individuals and organizations to try to do their thing as effectively as possible, sharing their experience, co-ordinating where they overlap or where they might conflict or duplicate one another, but not entrusting the activities to a large scale organization of any type, least of all to government.

Now, coming from the broad range of the tools that are available to those that are in the area of training and personnel development, which is the area occupied by the Centre for Developing Business, let us think about ways in which this effort may be put forward by such an insti- 
tution. As a university-based centre, it is not in the business of doing anything on a national basis or, least of all, supplanting other organizations which are trying to do that, but is in the business of trying to help other organizations to provide a centre for sharing experience and developing new ideas. I think the analogy of the role of a teaching and research hospital versus a general hospital is a useful one. In a teaching hospital new cures are designed and tested and developed, doctors are trained to use them and then they are made available, the doctors, and the cures, for application throughout the country. In the course of doing this, many patients are cured and perhaps a few are killed, but the teaching hospital does not see its role as taking care of the health needs of the whole community. So the role of the Centre is to develop and test new approaches for the promotion of small enterprise and business in gencral and then to disseminate them and to train others to, in turn, implement them in their own institutions. So let us now look at the broad outline of the proposal we have put to you.

The idea is to take the four potential approaches that are listed 1 to 4 (see Appendix) and to measure their cost and benefits, to improve them because they are based either on things that are already happening here or developed elsewhere, and then to evolve and disseminate models of them for use elsewhere and to train people to make use of them. I will say in a moment a little bit more about the detail of each of them. Let me just explain why it was felt necessary to measure the costs and benefits of each. Quite often in this as in other fields people say 'I am doing it, why shouldn't I go on doing it, why need they tell me if it is useful or not?' and indeed small enterprise promotion is one of the few activities, or one of the regrettably increasing number of activities, that is often evaluated by numbers or by the amount of money that is spent on it rather than by the benefits it achieves. Now what we are trying to do is to take four possible approaches which I shall explain in more detail in a moment, to small business development, and do to them what you as businessmen do in regard to your every activity. Namely, to measure the profit or loss involved in doing that and in the same way for each of your divisions or activities if you expect to see monthly, quarterly or at the very least annually, some measurement not only of what you spend on them, but what is achieved by them in terms of revenue. So with these four possible approaches to small business development we are trying to evolve the most effective way of applying them in this environment in order to measure their cost and benefits and to produce a profit and loss account for each. Also, particularly as a result of the lower-level counselling service which I will explain in a bit more detail in a moment, it is hoped to gain a lot more information about the small business sector, because one thing which has surprised me in the 10 days I have been here, is that when I have made statements about, for instance, the profitability of small enterprise or asked questions about small enterprise in general, nobody has been able to answer my questions. No one has been able to contradict my foolish statements. There doesn't seem to be very much information about the small enterprise sector in this country and I think this is necessary as a basis for promotion and indeed as a basis for generally defining the role of small business in the economy.

Now can we look in a little more detail at each of these four approaches. First of all - entrepreneurship development. I referred a moment ago to the need not only to help existing businesses but, perhaps more important, to create new business. The idea is to enable young people, who are presently un- or under-employed, to start their own businesses, by doing four things for them viz, by

- inculcating the desire to improve their own situation,

- introducing them to basic management techniques, techniques of starting their own enterprise,

- helping them to develop a plan for a viable venture,

- and assisting them, not actually obtaining for them, and this distinction is important I think, to obtain for themselves the necessary resources they need.

It might be argued that this is an attempt to create a silk purse out of a sow's ear but, in fact, there is welldocumented and world-wide experience in the U.S.A., Britain and India and no end of countries about this sort of activity and, in fact, what we are planning to do is to take 20 carefully selected young men who fall into the category of presently un- or under-employed and to submit them to something like three months of training, or training and personal development, covering those four areas. The training is based on world-wide experience in a number of extraordinarily different environments, and one can be fairly confident that at least 10 of them will, at the end of the year - that is nine months after they have finished the training - be in businesses which have a good chance of succeeding and carrying on in business for many years and employing other people. This, as I say, represents the application of a methodology which has been widely tested and developed and made applicable to a large number of different societies. So that is entrepreneurship development. And it surprises me, given the vast amount of activity that is going on in this country, it may well be that people are already doing this sort of activity, but I haven't come across it and nobody has said that it is already being done.

The second programme is what we have called lowerlevel counselling. Now, this is sometimes characterized as trying to train the blind to lead the blind, but it is an area in which I have had particular experience. It is, I believe, being done here in a way by some Church-based groups etc., but I could spend a moment perhaps on describing the work I did originally in Kenya. I was providing what one might call higher-level counselling such as is being provided here and which we can talk about in a moment. I have come to the conclusion that perhaps it was not a very cultivated way of doing things, in any case I had other things to do, and so I then evolved a system whereby people without any sort of qualifications, experience or contacts could perhaps do something and although not the same, it would be of some benefit to the enterprise being advised.

I eventually devised and tested a system whereby people who were not matriculants but had just four years of secondary education, were able, with about eight weeks of training, to make a very definite and measurable improvement over a period of over six months, to 30 or 40 
small enterprises each. Not very dramatic, just simple, basic improvements, not making an enormous difference to any of the enterprises but with the advantage of being at a rather low cost, for they were not highly qualified people. Also they were capable of a wide outreach making it possible now, in fact, for the programme to be implemented on a far wider basis in Kenya and a number of other countries. Important too is that whilst it doesn't make an enormous difference to any one enterprise, it makes a small difference to a large number. What one might characterize as an egalitarian approach to small business development, working particularly with small businesses whose owners often for reasons of time, location or education, are unable to learn very much in a classroom. This kind of approach can be very effective with illiterate people who cannot gain much from classroom instruction. I do not know if this will definitely work in this country and this is the reason for trying to see whether it will. The idea is to take three or four young matriculants, to train them according to the procedures that have been developed elsewhere, with suitable modification, to give them 20 or 30 clients each to measure the employment, profitability and turnover of private enterprises before and after something like nine months or 12 months of work with them, to measure the difference and improvement and to compare that with the cost of supplying such a service. It is also felt that as a by-product of this approach, they will gather a lot of information about the small business sector, filling the gap that I mentioned earlier.

But it is rarely evaluated in terms of difference it really makes to the employment, profits and turnover of the enterprises which are managed by those who have been trained. The intention is to provide that sort of evaluation to measure the costs and the real benefits, not necessarily in terms of the nice thanks and warm feelings of the participants, but of the actual improvements in the enterprises. This in brief describes the four activities which are included in this programme.

Let me just attempt to summarize the results which we hope will arise from this. First of all, it is hoped that as a result of this programme, models for each of the four types of intervention will be developed, not merely incorporating international experience or the work that is already being done, but incorporating improvements which will be evolved both before the programmes are started and while they are being run and these will be made available to other individuals and organizations, whether to publish manuals, or to organize seminars, workshops or whatever media appropriate for disseminating information about this or that method of promoting small enterprise. Considerable data should be gathered about which of these four methods can achieve which particular types of objective.

The Centre for Developing Business should be in a position to provide a trainer/training facility so that any organization, or indeed individual, who is interested in running entrepreneurship development programmes, organizing higher- or even lower-level counselling, or getting into, or who is already in the training field, can make use of the expertize thus gathered by the Centre, and can send its people for training there so that they can gather whatever has been learned during the course of the pro- gramme described. That, briefly, perhaps too hastily, describes what we have in mind.

\section{Appendix}

\section{The proposal}

- To measure the costs and benefits.

- To improve the content.

- To evolve and disseminate models of:

Entrepreneurship development, start your own business programme (To be undertaken by CDB/UP)

Lower-level counselling service (To be undertaken by $\mathrm{CDB}$ )

Higher-level counselling service (As being provided by urban foundation and others)

Training programmes (As being provided by CDB and others)

- To find out more about small businesses.

\section{Lower-level counselling}

To enable owners/managers of existing businesses to improve their own profitability through simple management techniques and the development of the ability to make and implement their own decisions.

- Counsellors are matriculants with no formal business experience.

- They are trained in simple techniques of diagnosis and assisting clients to solve their own problems.

- They are closely and regularly supervised, following preset procedures.

- A low-level intervention, providing an economical and marginal improvement to large numbers of businesses.

\section{Higher-level counselling}

To assist a limited number of businesses to obtain finance, raw materials, premises, orders and to break through bureaucratic barriers.

- Counsellors are experienced managers from large private sector companies.

- Extensive use is made of personal contacts and influence at the highest level.

- The cost of counselling is often covered by large companies, or through individual counsellor's goodwill.

- Assisted enterprises can radically change and improve their situation.

\section{Training programmes}

To enable owners/managers of existing businesses to manage their businesses more effectively.

- To improve knowledge and skills.

- To motivate and encourage a positive approach.

- Content and learning methods oriented towards practical applicable skills.

- Brief individual on-site follow-up to maximize application. 


\section{Entrepreneurship development}

To enable young people who are presently un- or underemployed to start their own businesses.

- Inculcating the desire to improve their own situation.

- Introducing them to the basic techniques for starting and managing their own businesses.

- Assisting them to develop a viable business plan for their own venture.

- Assisting them to obtain for themselves the necessary resources such as finance, premises and equipment.

\section{Results}

- 'Models' for effective entrepreneurship development, high- and low-level counselling and classroom training, for the use of interested organizations.

- Information on the cost-effectiveness and results of each of the four approaches.

- Data about the small business sector.

- A trainer and counsellor training facility for institutions mounting their own programmes. 